\title{
Mechanical characterization of PM aluminum composites by small punch test
}

\author{
Mario Fredy Moreno ${ }^{1}$, Martin Balog ${ }^{2}$, Peter Krizik ${ }^{2}$
}

\author{
${ }^{1}$ CONICET- Física de Metales- Centro AtómicoBariloche - (8400), Bariloche, Río Negro, Argentina. \\ e-mail: mmoreno@cab.cnea.gov.ar \\ ${ }^{2}$ Institute of Materials and Machine Mechanics, Slovak Academy of Sciences, Dubravska cesta 9, 84513, Bratislava, \\ Bratislava, Slovak Republic. \\ e-mail: martin.balog@savba.sk; peter.krizik@savba.sk
}

\section{ABSTRACT}

In this work Small Punch Test (SPT) was applied to study the mechanical behavior of ultrafine-grained Al$\mathrm{Al}_{2} \mathrm{O}_{3}$ metal matrix composites (MMCs) fabricated in situ via powder metallurgy route (HITEMAL ${ }^{\circledR}$ ). Such MMCs show attractive mechanical properties, enhanced creep performance and increased thermal stability at elevated temperatures, not normally associated with service of conventional $\mathrm{Al}$ alloys, even after prolonged high temperature exposure. MMCs fabricated from two powders of different particle size $\left(\mathrm{d}_{50}=8.9\right.$ and $1.2 \mu \mathrm{m})$ were evaluated in the present work.

SPT was performed at room temperature using disc-shaped specimens of $10 \mathrm{~mm}$ in diameter. The effect of the different disc thickness $(0.4,0.5$ and $0.6 \mathrm{~mm})$ on the load vs. displacement function was evaluated. The displacements monitored from top and bottom sites of the specimen varied during the course of the test. The discs deformed throughout the test by two plastic stages, typical for ductile materials. The relation between load-displacement and stress-strain tensile curves for both composites was analyzed. A drastic change of mechanical behavior between the green compact of cold pressed material and the hot forged material was detected.

New methods of determination of a characteristic load $\mathrm{P}_{\mathrm{Y}}$, which represents a transition from elastic to plastic bending regime were presented and discussed. A relationship between $\mathrm{P}_{\mathrm{Y}}$ and corresponding yield stress was studied for each composite material by a calculation of their respective correlation parameters.

Keywords: Small punch test, powder metallurgy, yield strength, aluminum, composite, correlation parameter.

\section{INTRODUCTION}

The HITEMAL ${ }^{\circledR}[1,2]$ are $\mathrm{Al}-\mathrm{Al}_{2} \mathrm{O}_{3}$ metal matrix composite (MMC) materials fabricated through powder metallurgy $(\mathrm{PM})$ consolidation of fine atomized $\mathrm{Al}$ powder with mean particle size of 1-10 $\mu \mathrm{m}$. The nanoscale $\mathrm{Al}_{2} \mathrm{O}_{3}$ forms in situ and stems from native amorphous (am)- $\mathrm{Al}_{2} \mathrm{O}_{3}$ layers on as-atomized feedstock $\mathrm{Al}$ powders. One of the PM processes comprises consolidation through the hot quasi-isostatic forging (QIF) of cold compacted powders. The resulting microstructure of QIFed HITEMAL consists of continual special nano-thick am- $\mathrm{Al}_{2} \mathrm{O}_{3}$ network embedded in ultra-fine grained $\mathrm{Al}$ matrix. QIFed HITEMAL shows high strengths at elevated temperatures not normally associated with use of conventional $\mathrm{Al}$ alloys and superior structural stability after prolonged exposures up to $400{ }^{\circ} \mathrm{C}$, which predetermines these materials for a potential use especially in application at elevated temperatures where excellent creep resistance is required. The spreading of native oxide skin coming from elementary aluminum particles play a key role in the reinforce mechanism of these composites [2]. Such nature and spreading characteristics of the amorphous and crystalline oxide reinforce nanoparticles are strongly dependent of the raw powders and the PM processes [1].

SPT has been applied since 80 decade to study the embrittlement of structural components in the nuclear plants due to the aging processes mainly by radiation [3]. For a purpose of sampling from a component under service a small amount of testing material from components surface was non-destructively extracted. The mechanical characteristics are then determined by penetration tests realized on small disks. Disks of 10 or $3 \mathrm{~mm}$ in diameter were employed with respective thicknesses of 0.500 and $0.200-0.250 \mathrm{~mm}$. 
SPT provides the mechanical behavior via a load $(\mathrm{P})$ vs. displacement $(\delta)$ plot. The punch plot is obtained from the controlled indentation of a hemispherical punch (or ball) in the center of the disk specimen. Such response is representative of the mechanical strength and deformation behavior. The potential of this technique lies on the fact that the big reduction of volume of material for specimen, which allows a high selectivity of sampling, contrary to the traditional techniques (tensile, fracture toughness or creep for example) that need large volume of material. This selectivity improves the sampling efficiency in case of limited amount of laboratory materials. The disadvantage of SPT is the lack of a direct way to obtain traditional mechanical properties from this novel technique. That is, due to a complex stress field along the test where the disk is subjected to multiple combination of loading modes, including indentation, elastic and plastic bending, and membrane stretching at different level of deformation [4]. The literature has attempted model by numerical methods in order to reproduce the elastoplastic processes in order to identify which parameters controls the deformation in different stages along the test $[4,5,6]$.

SPT has been applied in many engineering materials including metallic alloys and composites $[5,6,7]$ to correlate the SPT results with the traditional mechanical properties like tensile, fracture or creep. For that purpose some semiempirical correlations between SPT parameters extracted from load-displacement curve and tensile properties like yield strength, tensile strength and elongation are often reported [4, 7, 3]. Under this approach, the characteristic load $\mathrm{P}_{\mathrm{Y}}$ that represents the end of first regime (elastic bending) of SPT has been selected to be related with yield strength. This framework started by Mao and Takahashi [8] has been continued in recent studies [5,7] until these times. There are several definitions of $\mathrm{P}_{\mathrm{Y}}$ and its representativeness for the beginning of plasticity is still under debate. By the introduction of a correlation factor $\alpha$ a linear relation as $\sigma_{Y S}$ proportional to $\alpha \mathrm{P}_{\mathrm{Y}} / \mathrm{t}^{2}$ has been proposed; where $\mathrm{t}$ is the initial thickness of SPT specimen.

The present work is focused on clarifying the relationship between the yield strength and the characteristic load $\mathrm{P}_{\mathrm{Y}}$ in two HITEMAL compositions fabricated of two powders of 1.2 and $8.9 \mu \mathrm{m}$ mean diameter. The methodologies to evaluate the characteristic load $\mathrm{P}_{\mathrm{Y}}$ are discussed. Also, the differences among experimental methods to define the central displacement measurement are pointed out.

\section{MATERIALS AND METHODS}

Two different types of commercially available gas-atomized $\mathrm{Al}$ powders ( $\mathrm{Al}>99.8 \mathrm{wt} \%$ ) with $\mathrm{d}_{50}=1.2$ and $8.9 \mu \mathrm{m}$ were used for this study. Loose powders were cold pressed by cold isostatic pressing (CIP) at 200 $\mathrm{MPa}$. The forging blanks with diameter of $\varnothing 86 \mathrm{~mm}$ and height of $75 \mathrm{~mm}$ were machined from CIP green compacts. The forging blanks were subjected to vacuum degassing at $420{ }^{\circ} \mathrm{C}$ for $12 \mathrm{~h}$ at $5 \cdot 10^{-2} \mathrm{~Pa}$ prior to forging. Degassed forging blanks were heated in air to the forging temperature of $420{ }^{\circ} \mathrm{C}$ and held at that temperature for $60 \mathrm{~min}$. QIF compaction with a limited amount of induced deformation was performed using a Lasco SPR 1000 screw press with an impact energy of $57 \mathrm{~kJ}$ and a maximal initial strain rate of $7.3 \mathrm{~s}^{-1}$. The forging die was preheated to $110{ }^{\circ} \mathrm{C}$. The die walls were lubricated with a graphite water solution [2]. As "hot forged" condition samples of 1.2 (F12) and $8.9 \mu \mathrm{m}$ (F89) were cut and machined by turning cylinders of $10 \mathrm{~mm}$ in diameter to obtain SPT specimens. Disks of $1 \mathrm{~mm}$ were cut by metallographic saw and mechanical polishing was made with emery paper up to 2000 grit. Specimens of $0.400,0.500$ and $0.600 \mathrm{~mm}$ in thickness were polished with thickness tolerance lower than $+-1 \%$. Small punch device is basically two halves of dies that locate the specimen by clamping or simple bend in a receiving hole. Reference [3] details the dies, their dimensions and systems to record displacements and load. The puncher is a ceramic ball of $2.5 \mathrm{~mm}$ in diameter pushed by a hard steel plunger. The Instron 5567 electromechanical testing machine was used to apply displacement at constant crosshead speed of $0.1 \mathrm{~mm} / \mathrm{min}$. SPT were performed up to maximum load for all cases. Special case of study was made for unclamped specimens of F12 material and the cold press material (CP12) before being subject to hot forging. Both materials were tested in order to study the changes in mechanical behavior. Two displacements were recorded during all tests: i) plunger displacement $\left(\delta_{\mathrm{EXT}}\right)$ measured with an extensometer MTS $25 \mathrm{~mm}$ gage length and ii) bottom face displacement $\left(\delta_{\text {Вот }}\right)$ measured with by a displacement transducer (HBM W1T3 +- $1 \mathrm{~mm})$. The transducer was coupled to a push rode in direct contact with the bottom face of the specimen. Load was monitored by an Instron load cell of $1 \mathrm{kN}$.

\section{RESULTS AND DISCUSSION}

\subsection{SPT behavior until $P_{\max }$}

The plots of figure 1a represent the mechanical behaviors obtained by SPT for F12 and F89 materials until maximum load $\mathrm{P}_{\mathrm{MAX}}$ (defined by an arrow). The displacements showed in these plots correspond to meas- 
urements from bottom face $\delta_{\mathrm{BOT}}$. This displacement allows capturing directly the pure movement of the center of the disk. Two tests per material were carried out in order to evaluate the reproducibility.

(a)

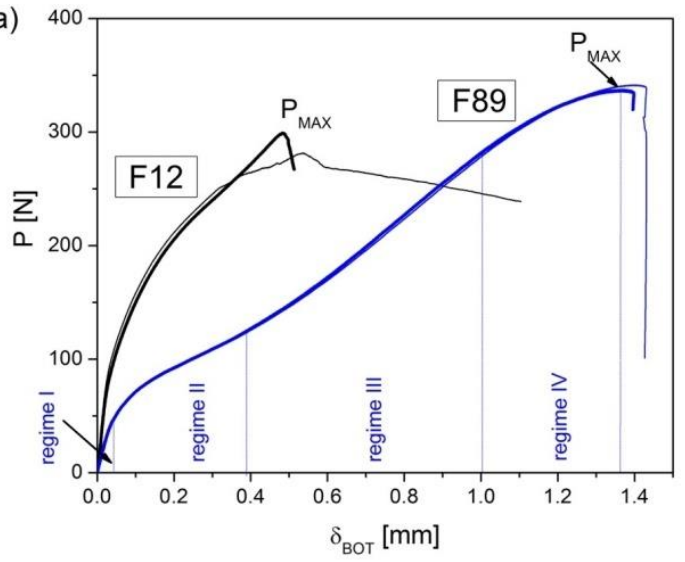

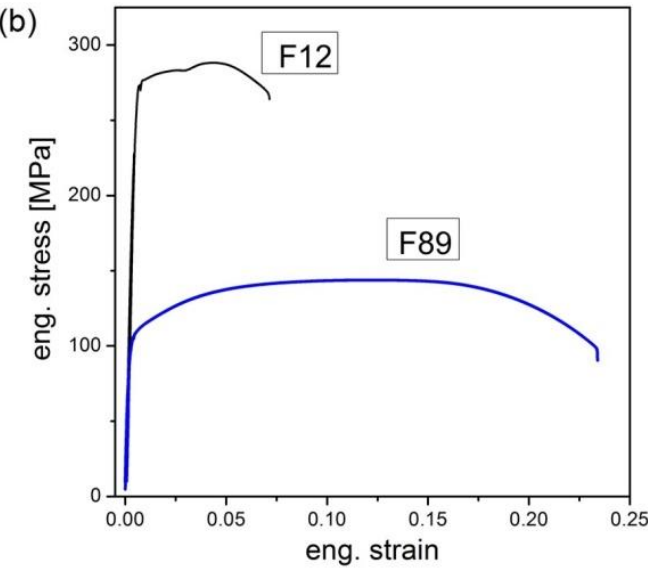

Figure 1: (a) SPT plots measured from $\delta_{\text {Вот }}$. Regimes of elastoplastic deformations are separated by fine dotted lines. (b) Typical plots of uniaxial tensile test.

The four deformation stages were developed in the case of F89: I- elastic bending, II- plastic bending, III- membrane stretching and IV-plastic instability before reaching maximum load $\mathrm{P}_{\mathrm{MAX}}$, as demonstrated by dotted lines in figure 1a. The results for F89 showed good reproducibility. The material F12 showed only the development of two stages followed by a sudden instability before reaching $\mathrm{P}_{\mathrm{MAX}}$ at shorter displacement. Moreover, F12 showed significant variations in terms of both $\mathrm{P}_{\mathrm{MAX}}$ value and the corresponding displacement for $\mathrm{P}_{\mathrm{MAX}}\left(\delta_{\mathrm{MAX}}\right)$. From several tests made on both materials the damage beginning could be clearly detected at $\mathrm{P}_{\mathrm{MAX}}$. If the ball is forced to penetrate after reaching $\mathrm{P}_{\mathrm{MAX}}$ the load started decreasing. That was a case of fine line plot of F12 showed in figure 1a, where a growing crack after reaching $\mathrm{P}_{\mathrm{MAX}}$ was confirmed in light microscope after unloading.

Figure $1 \mathrm{~b}$ shows the representative tensile behaviors obtained from uniaxial tests for F12 and F89. Data were taken from reference [1]. They showed that F89 has more than twice of maximum elongation $\varepsilon_{\text {UTS }}$ (eng. strain at ultimate tensile strength) respect to F12. A qualitative analyze suggests that the ratio between $\varepsilon_{\mathrm{UTS}(\mathrm{F} 89) /} \varepsilon_{\mathrm{UTS}(\mathrm{F} 89)}$ elongations obtained from uniaxial tensile tests was in agreement with the ratio of $\delta_{\mathrm{MAX}}$ ${ }_{(\mathrm{F} 89)} / \delta_{\mathrm{MAX}(\mathrm{F} 89)}$ obtained from respective SPT tests.

\subsection{Evaluation of bonding process by SPT}

Before to perform the hot forging, the green body (CP12) was obtained from cold compaction at 200MPa. In order to compare the mechanical states of CP12 and F12 unclamped tests were performed in specimens in $0.500 \mathrm{~mm}$ in thickness for both materials. Drastic difference in $\mathrm{P}_{\mathrm{MAX}}$ was obtained: $13 \mathrm{~N}$ for CP12 with a brittle behavior while $266 \mathrm{~N}$ was obtained for F12 with a ductile behavior followed by a development of damage. Two specimens of CP12 were tested under the same condition and three or four parts in a brittle manner were obtained. Figure 2 show a macroscopic view of both materials after tests. The difference in mechanical behavior reveals the strong bonding obtained during the hot forging. While a high density is obtained by cold compaction (isostatic pressing) in CP12, enough bonding between powder particles is not provided. In reference [9] it was discussed this phenomena for axial compaction of aluminum powder. Aluminum particles are subject to extremely high contact pressure leading to severe plastic deformation but the oxide film hinders the proper bonding between metallic particles. As powder is finer the barrier mechanism is increased due to higher surface density. In spite of pronounced brittleness of CP12, which was even too brittle to machine the specimens, SPT was a feasible technique to evaluate its mechanical properties. 


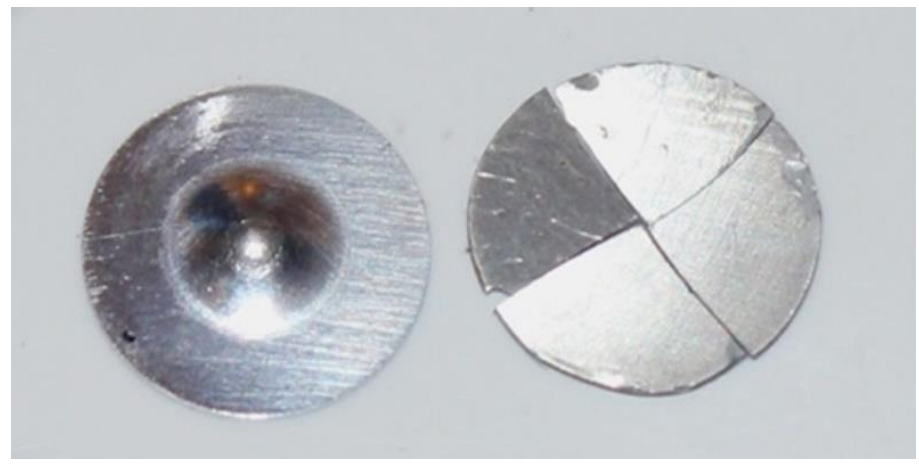

Figure 2: Optical micrograph of tested specimens of F12 (left) and CP12 (right).

\subsection{Displacement measurement methods}

Most of the publications represent SPT curves in terms of load (P) vs. punch displacement $(\delta)$. However, punch displacement is not good enough representative of a pure displacement derived from the contact point between ball and the specimen. Sometimes crosshead is computed as puncher displacement, while in other cases the transducer (extensometer or LVDT for instance) is attached directly to the puncher providing more isolated measurements. This way to measure could lead to compute extra displacements due to compliance of puncher (plus the ball if it used as indenter). Thus, if the puncher has low stiffness the recorded displacement is higher than the travel of the contact point of the indenter with specimen. In order to extract the pure displacement of the contact point a discount of elastic compliance should be done [4, 7, 10]. For the present work the two direct measurement are studied i) $\delta_{\text {Вот }}$ obtained directly from the extensometer attached and ii) $\delta_{\text {EXT }}$ which represent the recording by the extensometer. Figure $3 \mathrm{a}$ and $3 \mathrm{~b}$ shows the first and the transition to second regime of deformation for F89 and F12 respectively. It is noted for $\delta_{\mathrm{EXT}}$ coarse that is not linear from zero to low loads (indicated with the circle in the figures $3 \mathrm{a}$ and $3 \mathrm{~b}$ ). This behavior reflects plastic indentation of ball into disk due to a high effective contact pressure that leads to local yielding in a confined zone. In spite of compliance correction of $\delta_{\mathrm{EXT}}$ performed initial non linear coarse of the plot remains $[4,10]$.

(a)

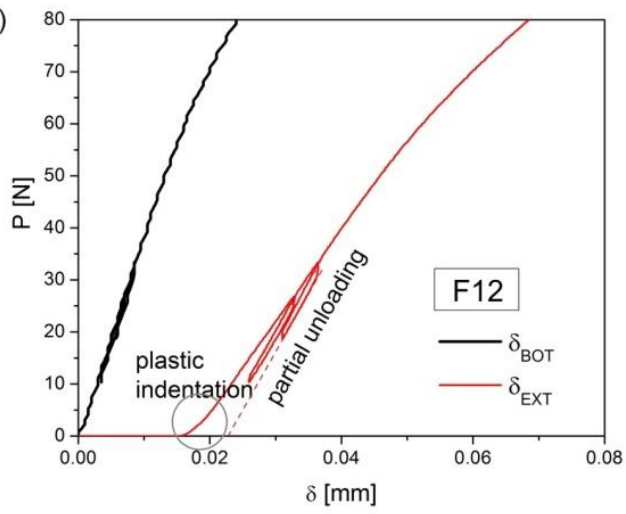

(b)

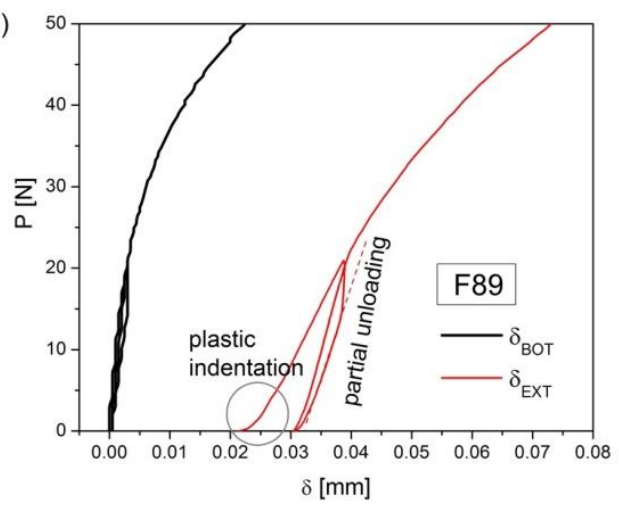

Figure 3: SPT plots for first and the transition to second regimens of deformation measured by from $\delta_{\text {Вот }}$ and $\delta_{\text {Вот }}$ for(a) F12. (b) F89. Both tests made in $0.500 \mathrm{~mm}$ thickness specimens.

In contrast when plots of figures $3 \mathrm{a}$ and $3 \mathrm{~b}$ are in function of $\delta_{\mathrm{BOT}}$, they show linear behaviors from the beginning, covering more extended range of load. In addition $\delta_{\mathrm{BOT}}$ reveals a higher slope of linear regime than that for $\delta_{\text {EXT. }}$. Therefore, a pure elastic behavior is detected during first regime when $\mathrm{d}_{\mathrm{BOT}}$ is used for SPT plots. In order to evaluate the elastic response of $\delta_{\text {вот }}$ partial unloadings were effected for both materials (two cycles for F12 and single for F89) during linear region. Coincident slope and linear behavior were obtained in the unloading cycle. In contrast, the slope of same unloadings of $\delta_{\mathrm{EXT}}$ resulted in higher than that for load curve (unloading cycle path is departure from initial curve in Figures $3 \mathrm{a}$ and $3 \mathrm{~b}$ ). It must be 
highlighted that only few works from open literature discuss this differences. Summarizing, it is highly recommended to evaluate the beginning of yielding by using the $\delta_{\mathrm{BOT}}$ on SPT plots.

\subsection{Relation of yield strength with SPT results}

The assessing of yield strength proposed by MAO and TAKAHASHI [8] uses the characteristic load $\mathrm{P}_{\mathrm{Y}}$ obtained from SPT. $\mathrm{P}_{\mathrm{Y}}$ represents the end of the elastic bending regime of a thin circular plate clamped and indented by a concentric load. The relation proposed for this mechanism is through a correlation parameter $\alpha$ as:

$$
\sigma_{Y S}=\alpha P_{Y} / t^{2}
$$

Different methodologies have been proposed to define $\mathrm{P}_{\mathrm{Y}}$. MAO and TAKAHASHI [8] defined $\mathrm{P}_{\mathrm{Y}}{ }^{\mathrm{MAO}}$ as the intersection of the representative lines of regimen I and II (labeled in figure 4a and 4b), elastic and plastic bending respectively. However this intersection $\mathrm{P}_{\mathrm{Y}}{ }^{\mathrm{MAO}}$ falls out from $\mathrm{P}$ vs. $\delta$ curve. Following a similar procedure suggested by the European Code [12] a vertical projection from $P_{Y}{ }^{M A O}$ was made to define a $\mathrm{P}_{\mathrm{Y}}{ }^{\text {MAO* }}$ [4].GARCIA et al [6] proposed an offset method defined by a parallel line to regime I shifted in displacement $t / 100$. The intersection is called $\mathrm{P}_{\mathrm{Y}}{ }^{\mathrm{t} / 100}$ is equivalent to engineering definition of $0.2 \%$ strain to calculate the yield stress. The cited definitions of $\mathrm{P}_{\mathrm{Y}}{ }^{\mathrm{MAO}}, \mathrm{P}_{\mathrm{Y}}{ }^{\mathrm{MAO}}{ }^{*}$ and $\mathrm{P}_{\mathrm{Y}}{ }^{\mathrm{t} / 100}$ are shown in figures $4 \mathrm{a}$ and $4 \mathrm{~b}$ for F12 and F89 respectively. It should be noted that another offset t/10 method is also found in the open literature [4,7]. For the present work only two definitions $\mathrm{P}_{\mathrm{Y}}{ }^{\mathrm{MAO}}$ and $\mathrm{P}_{\mathrm{Y}}{ }^{\mathrm{t} / 100}$ will be analyzed due to these respective load represent the beginning of plasticity [4]. Other authors assume that massive yielding is the right criterion to define the fully plastic behavior [7,12], that is the case of $\mathrm{t} / 10$ method.
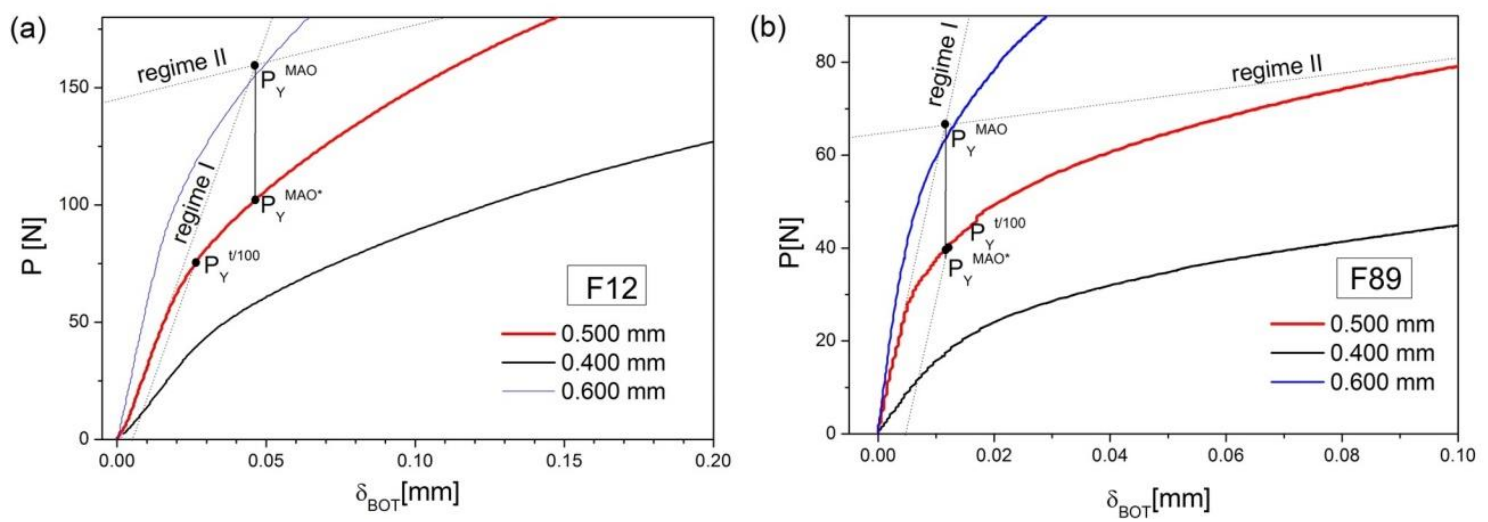

Figure 4: SPT plots for first and the transition to second regimen of deformation measured by from $\delta_{\text {Вот }}$ for (a)F12. (b)F89. Both tests were performed with0.400, 0.500 and $0.600 \mathrm{~mm}$ thickness specimens. 
(a)

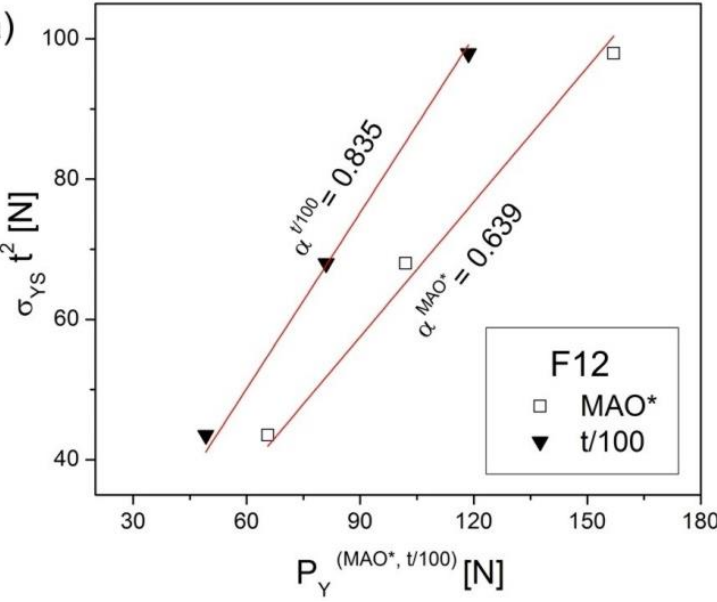

(b)

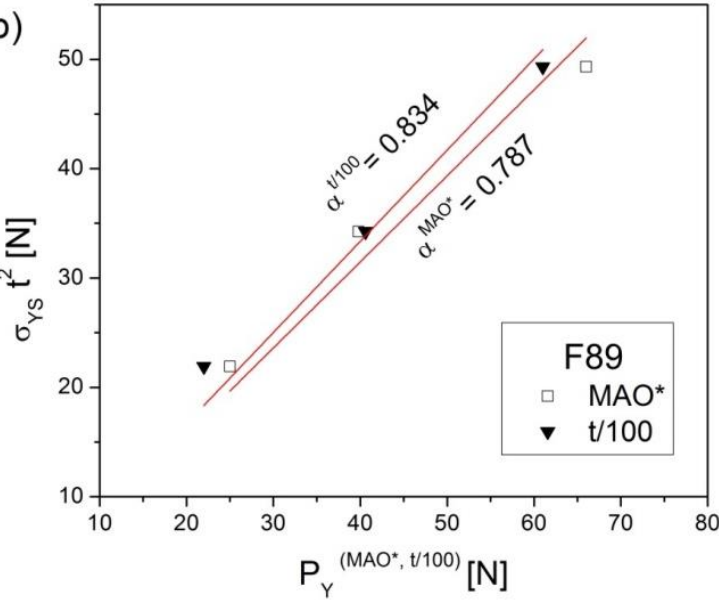

Figure 5: Linear fittings of equation (1) for (a)F12. (b)F89.

It is also noted that the effect of thickness variation has to be taken into account very carefully because small variations have strong incidence in load change in SPT curve. Thus, the accurate thickness variation has been accomplished during specimens preparation. The effect of thickness can be seen in the both material in figures $4 a$ and $4 b$ slopes of first regime are in accordance roughly as $\mathrm{t}^{3}$.

Assuming that this equation (1) is valid for different material thickness, the increase of $\mathrm{P}_{\mathrm{Y}}$ should compensate for $\mathrm{t}^{2}$ increment. From figures $5 \mathrm{a}$ and $5 \mathrm{~b}$ the collection of $\mathrm{P}_{\mathrm{Y}}$ for Mao* and $\mathrm{t} / 100$ methods were plotted for both composites. The linear fittings passing by zero for each material in terms of $\sigma \mathrm{t}^{2} \mathrm{vs}$. $\mathrm{P}_{\mathrm{Y}}$ was done. Good linearity was obtained for all fittings and the slopes of these fittings are the respective correlation parameters of equation (1). Similar correlation parameters close to 0.83 was obtained for both materials for $\mathrm{t} / 100$ method. On the one hand, there is no big difference in respect to choose method for the case of F12. On the other hand, the physical meaning of $\mathrm{P}_{\mathrm{Y}}$ is still under debate $[4,7,10,12]$. A selection of $\mathrm{P}_{\mathrm{Y}}$ methodological criteria should be complemented with more detailed analyze of plasticity development across the whole specimen thickness. According to this work the t/100 method provides a better relation of uniaxial yield strength with SPT parameters.

\section{CONCLUSIONS}

Small punch test was used to evaluate mechanical behavior of two hot forged $\mathrm{Al}-\mathrm{Al}_{2} \mathrm{O}_{3}$ composites fabricated of 1.2 and $8.9 \mu \mathrm{m} \mathrm{Al} 99.8 \%$ powders. The disks specimens with the diameter of $10 \mathrm{~mm}$ and the thickness of $0.400,0.500$ and $0.600 \mathrm{~mm}$ were employed. The following conclusions are drown:

A sudden change from brittle to high mechanical strength ductile behavior was confirmed when cold compacted green body was compared to hot forged material. Such difference was due to the lack of bonding during cold compaction, while a relative high strength was found after hot forging. Therefore SPT is suitable to capture the both brittle and ductile behaviors in correspondence with such extreme values of mechanical strength.

- Indirect measurement of displacement from the top face of a specimen is distinguish ably different when compared to direct measurement from the bottom face.

- In order to identify a change in elastic response to the beginning of plastic behavior bottom displacement measurement is preferable, as neither calibration nor corrections are required in this case. The semi empiric relationship between the yield strength and the characteristic load $\mathrm{P}_{\mathrm{Y}}$ were pursued by using the correlation parameter $\alpha$. Two methods to calculate the characteristic load $P_{Y}$ : $i$, the offset $t / 100$ and, ii., the modified Mao were employed. For both composites a value of $\alpha=0.83$ was obtained using the $t / 100$ method. This criterion is suggested as most representative one as it allows detection of a beginning of plastic yielding during SPT. 


\section{ACKNOWLEDGMENTS}

Technical support from Metales Group (Centro Atómico Bariloche, CNEA Argentina) is recognized. Financial support from international project CONICET/SAS 2013-2014 is acknowledged. Financial support from the SRDA APVV-0556-12 project and the VEGA 2/0065/16 project is acknowledged.

\section{BIBLIOGRAPHY}

[1] BALOG, M., POLETTI, C., SIMANCIK, F., et al., "RajnerThe effect of native $\mathrm{Al}_{2} \mathrm{O}_{3}$ skin disruption on properties of fine Al powder compacts", J.of Alloys and Comp., v.509, pp. S235-S238, 2011.

[2] BALOG, M., KRIZIK, P., NOSKO, M. "Forged HITEMAL: Al-based MMCs strengthened with nanometric thick $\mathrm{Al}_{2} \mathrm{O}_{3}$ skeleton", Materials Science \&Engineering, v. A613,pp. 82-90, 2014.

[3] MANAHAN, M.P., ARGON, A.S., HARLING, K.O. "The Development of Miniaturized Disk Bend Test for the Determination of Post Irradiation Mechanical Properties", J. Nucl. Mater., v. 104, pp.1545-1550, 1981.

[4] MORENO, M., BERTOLINO, G., YAWNY, A. "The significance of specimen displacement definition on the mechanical properties derived from Small Punch Test”, Mat. Des., v. 95, pp. 623 - 631, 2016.

[5] PEÑUElAS, I., CUESTA, I., BETEGÓN , C. "Inverse determination of the elastoplastic and damage parameters on small punch tests", Fatigue FractEng M, v. 32, pp. 872-885, 2009.

[6] ABENDROTH, M., KUNA, M. "Determination of Ductile Material Properties by Means of the Small Punch Test and Neural Networks", Advanced Engineering Materials, v. 6, vn.7, pp. 536-540, 2004.

[7] GARCÍA, T.E.., RODRÍGUEZ, C., BELZUNCE, F.J. "Estimation of the mechanical properties of metallic materials by means of the small punch test", J Alloys Compd, v. 582, pp.708-717, 2014.

[8] MAO, X., TAKAHASHI, H. "Development of a further-miniaturized specimen of $3 \mathrm{~mm}$ diameter for tem disk small punch tests", J Nucl.Mater.,v. 150, pp. 42-52, 1987.

[9] MORENO, M. F., González Oliver, C. J. R. "Densification of Al powder and Al-Cu matrix composite (reinforced with $15 \%$ Saffil short fibres) during axial cold compaction", Powder Technology, v.206, pp.297$305,2011$.

[10] MORENO, M. F. "Application of small punch testing on the mechanical and microstructural characterizations of P91 steel at room temperature", Int. J. Press.Vess.Pip., v. 1-9,pp. 142-143, 2016.

[11] CEN Workshop Agreement, "Small punch test method for metallic materials". CWA 15627:2006 E. Brussels: CEN; 2007.

[12] HURST, R.C., MATOCHA, K., "Renaissance in the use of the small punch testing technique", Proceedings of the ASME 2015Pressure Vessels and Piping Conference PVP2015, Boston, Massachusetts, USA, July 19-23, 2015. 